\title{
Evaluation of Efficacy and Safety of Oral Fixed-dose Combination of Probiotics in Bacterial Vaginosis
}

\author{
Arif A Faruqui ${ }^{1}$, Deepti Chitra ${ }^{2}$
}

\begin{abstract}
Aim: To evaluate the efficacy and safety of the vaginal-specific lactobacilli strain in management of bacterial vaginosis (BV). Materials and methods: A nonrandomized, open-labeled, noncomparative, multicentric study was conducted in a total of 58 female patients suffering from BV. Each patient was administered a combination of four strains of lactobacilli. Vaginal pH, discharge, odor, itching, and painful urination were performed at baseline, week 2 , and week 4 as assessment parameters.

Results: At the end of the study, data were extractable in only 56 females (mean age was $34.57 \pm 11$ years). Associated BV symptoms like vaginal discharge, odor, and painful urination reduced significantly at week 4 as compared to baseline. The most frequently encountered symptoms were vaginal discharge, vaginal $\mathrm{pH}$, odor, and itching. With a shift in $\mathrm{pH}<4.5$, at the end of week 4 all females showed improvement in the vaginal microbiota. Tolerability of fixed-dose combination was found to be good and none of the subjects discontinued the treatment.

Conclusion: Probiotic combination of vaginal-specific probiotic strains was found to be effective and safe for use in females who suffer from BV. Clinical significance: Lactobacilli have been found in very low numbers in women suffering from BV. After supplementing probiotic, mere fall in $\mathrm{pH}<4.5$ indicates probable colonization of the vagina with a specific strain of lactobacilli has helped in production of lactic acid and restoration of the vaginal microflora.
\end{abstract}

Keywords: Bacterial vaginosis, Lactobacillus, Microbiota restoration, Probiotic.

Journal of South Asian Federation of Menopause Societies (2019): 10.5005/jp-journals-10032-1185

\section{INTRODUCTION}

Infections of the vagina and outer female genitals include conditions caused by bacteria, viruses, cancer, noncancerous tumors and tissue growths, foreign bodies, or fistulas (abnormal passages between organs or an organ and a body cavity that allow fluids to pass from one to the other). These infections include: ${ }^{1}$

- Bacterial vaginosis (BV), which represents about $60 \%$ of all vaginal infections.

- Yeast infections, which account for 30-35\% of vaginal infections.

- Trichomonas vaginitis, which is responsible for $5-10 \%$ of vaginal infections. ${ }^{1}$

Bacterial vaginosis is the most common cause of abnormal vaginal discharge among women of childbearing age and is associated with adverse obstetric and gynecologic outcomes. Prevalence of $\mathrm{BV}$ among women of the reproductive age group is around $31.5 \%{ }^{2}$

Vulvovaginal infections are associated with decrease or absence of protective lactobacilli, which are normally present in the vagina. Lactobacilli produce lactic acid from glycogen, maintaining the vagina's acidic $\mathrm{pH}(<4.5)$. The acid environment inhibits the growth of other bacterial species found in the vagina in low levels. When lactobacilli are lacking, overgrowth of bacteria, such as Haemophilus spp., Gardnerella vaginalis, Bacteroides spp., Mycoplasma hominis, Mobiluncus spp., peptostreptococci, Ureaplasma, and other anaerobes can occur. ${ }^{3}$

Common symptoms are inclusive of increased vaginal discharge (white or gray in color) that often smells like fish, burning with urination and mild itching.

\section{Lactobacilli in Vaginal Flora}

More than 20 species have been detected in the vagina. The healthy vaginal microflora does not contain high numbers of many different
${ }^{1}$ Department of Pharmacology, Bhabha Hospital, Bandra West, Mumbai, Maharashtra, India

${ }^{2}$ Department of Obstetrics and Gynaecology, RNT Medical College, Udaipur, Rajasthan, India

Corresponding Author: Arif A Faruqui, Department of Pharmacology, Bhabha Hospital, Bandra West, Mumbai, Maharashtra, India, Phone: +91 9322429615, e-mail: godsgift070110@gmail.com

How to cite this article: Faruqui AA, Chitra D. Evaluation of Efficacy and Safety of Oral Fixed-dose Combination of Probiotics in Bacterial Vaginosis. J South Asian Feder Menopause Soc 2019;7(2):62-65.

Source of support: Nil

Conflict of interest: None

species of Lactobacillus. The main hydrogen peroxide-producing strains of lactobacilli are $L$. crispatus and L. jensenii. L. iners and L. gasseri are also among the dominant species of the vaginal microflora. 4

\section{Role of Lactobacilli in Vaginal Flora}

The main mechanism of lactobacilli in the vaginal flora is to prevent the overgrowth of pathogenic and opportunistic organisms. The presence of lactobacilli in vaginal epithelium is responsible for maintaining the vaginal $\mathrm{pH}<4.5$, which makes the condition unfavorable for the pathogen growth and sustainability. ${ }^{5}$

Bacterial vaginosis may coexist with candidiasis. In a study conducted by McClelland et al., it was observed that $26.9 \%$ of women with vulvovaginal candidiasis (VVC) had concurrent BV. ${ }^{5}$

Probiotics can be an effective treatment for dysbiotic conditions. Probiotic therapy addresses the cause of dysbiosis by restoring the ecological equilibrium of the urogenital tract. They 
may represent a superior approach to treating BV during pregnancy, especially since antibiotic therapy has been determined to be neither useful nor warranted.

Although lactobacilli spp. are most commonly administered through vaginal suppositories, oral substitution represents a patient-friendly concept for the restitution of a normal vaginal microbiota. In this study, we aimed to determine whether there is an effect of an orally administered preparation of four Lactobacillus spp. (L. crispatus, L. rhamnosus, L. gasseri, L. jensenii) on the vaginal microbiota of women suffering from BV. ${ }^{6}$

\section{Materials and Methods}

\section{Design and Participants}

A nonrandomized, open-labeled, noncomparative, multicentric study was conducted to determine the effectiveness of probiotic combination for 4 weeks. A total of 58 female patients, reporting to gynecologists, were screened for vaginal $\mathrm{pH}$, discharge, odor, itching, and painful urination.

\section{Inclusion Criteria}

Females were screened on the basis of vaginal $\mathrm{pH}$ and discharge odor. A pH strip with a narrow range of 3.5-6.0 manufactured by Analab Scientific India was used to determine the vaginal $\mathrm{pH}$ during screening. All females having history of vaginal discharge, vaginal $\mathrm{pH}>4.5$, and fishy or unpleasant odor were enrolled in the study.

Each patient was administered with a combination of lactobacilli strain (L. crispatus 1 billion CFU, L. rhamnosus 1 billion CFU, L. gasseri 30 million CFU, L. jensenii 20 million CFU) for 4 weeks.

\section{Exclusion Criteria}

Included patients with any of the several conditions listed as follows: Subjects with planned surgery during the treatment course or undergone surgery prior to 3 months of enrollment.

Patients who were pregnant or planning to conceive and lactating mothers were excluded from the study.

\section{Ethical Human Considerations}

This was a postmarketing surveillance study for already marketed formulation of the fixed-dose combination of L. crispatus 1 billion CFU, L. rhamnosus 1 billion CFU, L. gasseri 30 million CFU, and L. jensenii 20 million CFU, hence only consent was taken from the patients in their vernacular language. The study was conducted in accordance with the Declaration of Helsinki and at 16 centers across the country.

\section{Results}

At the end of the visit (week 4), data were extractable in 56 females with BV. There were 2 females with loss to follow-up and hence safety evaluation has been conducted in all 58 females but the efficacy analysis was conducted in 56 females who completed the study for all visits. Percentage reduction in parameters associated with BV is represented in Tables 1 and 2; and Figures 1 to 3.

The baseline and subsequent visit data stating relief in BV symptoms are presented in Table 1. At baseline, all females had vaginal discharge with fishy or unpleasant odor and were suffering from dysbiosis, which was confirmed by the $\mathrm{pH}$ test. Figure 1 depicts a significant reduction in discharge odor from baseline, where all females complained of either fishy $(51.7 \%)$ or unpleasant smell (48.3\%), while on week 4 none of the females had either discharge or odor complaint, which concludes that the probiotic supplement
Table 1: Baseline and follow-up evaluation of the effect of the probiotic in bacterial vaginosis

\begin{tabular}{|c|c|c|c|}
\hline Parameters & $\begin{array}{l}\text { Baseline (day 0) } \\
(\%)(n=58)\end{array}$ & $\begin{array}{l}\text { Week } 2 \text { (day 14) } \\
\text { (\%) }(n=58)\end{array}$ & $\begin{array}{l}\text { Week } 4 \text { (day 28) } \\
(\%)(n=56)\end{array}$ \\
\hline \multirow{2}{*}{$\begin{array}{l}\text { Homogeneous } \\
\text { vaginal discharge }\end{array}$} & 100 & Present $=36.2$ & Present $=0$ \\
\hline & & Absent $=63.8$ & Absent $=100$ \\
\hline \multirow[t]{2}{*}{$\mathrm{pH}$ of vagina } & $>4.5=100$ & $<4.5=81.0$ & $<4.5=96.4$ \\
\hline & & $>4.5=19.0$ & $>4.5=3.6$ \\
\hline \multirow[t]{2}{*}{ Odor } & Fishy $=51.7$ & Present $=18.9$ & Present $=0$ \\
\hline & $\begin{array}{l}\text { Unpleasant = } \\
48.3\end{array}$ & Absent $=81.0$ & Absent $=100$ \\
\hline \multirow[t]{2}{*}{ Itching } & Absent $=20.7$ & Absent $=86.2$ & Absent $=98.2$ \\
\hline & Present $=79.3$ & Present $=13.8$ & Present $=1.8$ \\
\hline \multirow[t]{2}{*}{ Painful urination } & Yes $=44.8$ & Yes $=3.4$ & Yes $=1.8$ \\
\hline & $\mathrm{No}=55.2$ & $\mathrm{No}=96.6$ & $\mathrm{No}=98.2$ \\
\hline
\end{tabular}

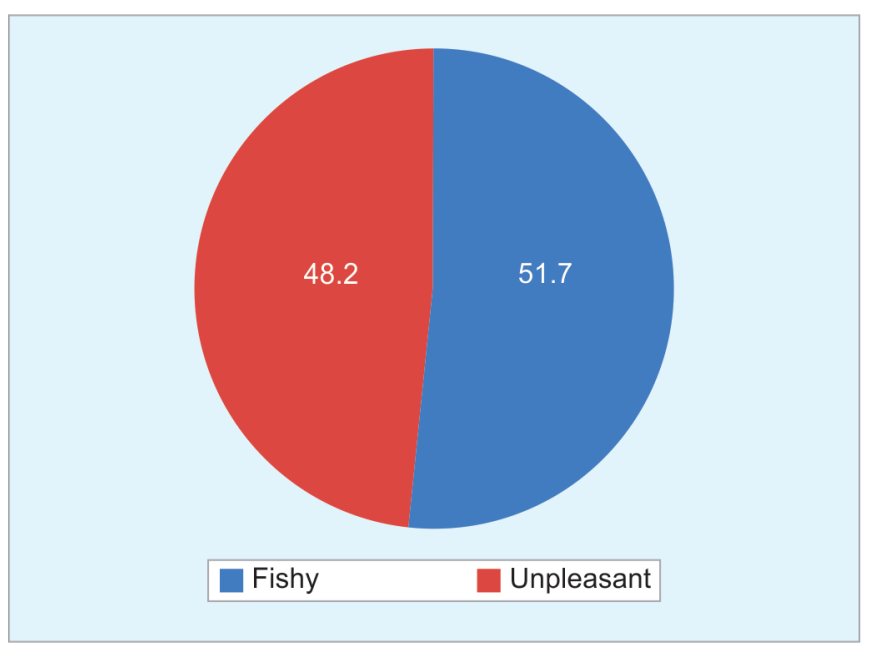

Fig. 1: Vaginal discharge odor

is effective in eradicating the major symptoms of BV. At baseline, all females were having vaginal $\mathrm{pH}>4.5$, which significantly reduced at week $2-19.0 \%$ and at week 4 , only $3.6 \%$ females had $\mathrm{pH}>4.5$ (Fig. 2). The change in vaginal $\mathrm{pH}$ enlightens the fact of restoring the vaginal microflora by the probiotic supplement that is responsible for maintaining the $\mathrm{pH}<4.5$.

About $79.3 \%$ of females had complaint of itching, which reduced at week $2-13.8 \%$ and at week 4 only $1.8 \%$ had complained of itching (Fig. 3).

At the end of the study visit, a global assessment was done by investigators by rating efficacy and safety as excellent, good, or poor (Table 2). About $71.4 \%$ of investigators termed that the probiotic had shown excellent results in terms of efficacy and $60.3 \%$ and $39.7 \%$ rated as excellent and good in terms of safety profile, respectively.

\section{Discussion}

Urogenital infections not caused by sexual transmission, namely yeast vaginitis, BV, and urinary tract infection, remain a major medical problem in terms of the number of women afflicted each year. $^{7}$

When the vaginal flora is examined, it is known that microorganisms of Lactobacillus spp. are dominant bacteria and 


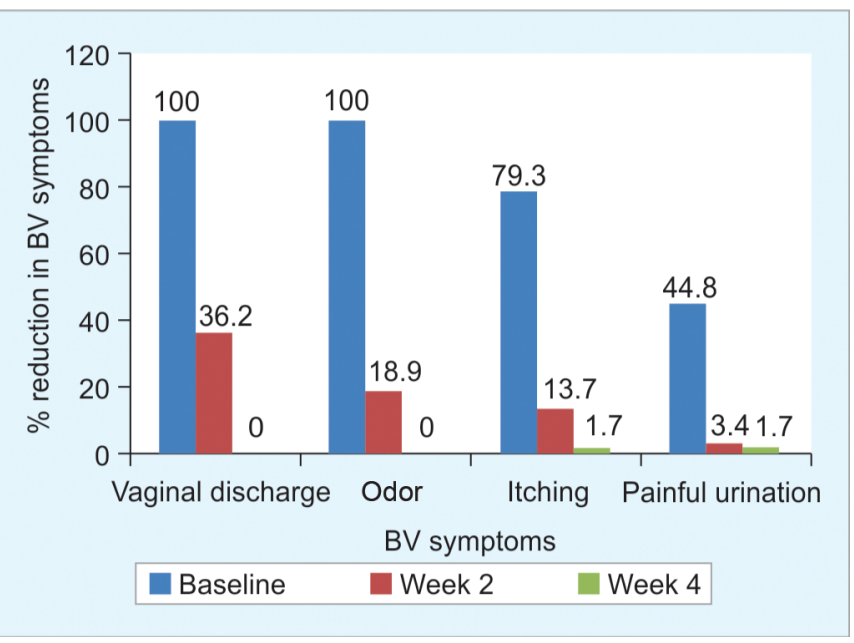

Fig. 2: Effect of probiotics in relieving bacterial vaginosis symptoms

Table 2: Global assessment done by investigators

\begin{tabular}{llll}
\hline & Excellent (\%) & Good (\%) & Poor \\
\hline Efficacy & 71.4 & 28.6 & None \\
Safety & 60.3 & 39.7 & None \\
\hline
\end{tabular}

form the urinary microbiota that demonstrates antimicrobial activity. ${ }^{8}$

The recurrence rate of $B V$ remains high with use of antimicrobials and such treatments are not designed to restore the lactobacilli. Antimicrobial drug resistance remains a root cause for BV recurrence. $^{9}$

Women with recurrent $\mathrm{BV}$ are at high risk of acquiring candida superinfection, both in the form of asymptomatic and symptomatic episodes. Bacterial vaginosis is the most common associated infection with candidiasis. ${ }^{10}$

Treatment of recurrent vaginal infections requires long-term antimicrobial prophylaxis, which results in increase in emergence of antimicrobial resistance; this suggests the need of natural alternatives for its treatment. Clinical studies have demonstrated that oral administration of Lactobacillus can demonstrate its effects after reaching the vagina. ${ }^{8}$

Probiotics do not cause antibiotic resistance and may offer other health benefits due to vaginal recolonization with lactobacilli. ${ }^{11}$

This study further strengthens the fact that supplementation of the vaginal-specific probiotic addresses the root cause of BV and its associated complications. The mere fall in $\mathrm{pH}<4.5$ indicates probable colonization of the vagina with specific strain of lactobacilli has helped in production of lactic acid and therefore enabling a fall in $\mathrm{pH}$ and restoration of the vaginal microflora.

Same has been demonstrated in earlier studies conducted in females suffering from BV using vaginal-specific probiotic increases the lactobacilli count within 1 week. ${ }^{12,13}$

Probably in future, probiotics can become the mainstay of therapy either alone or in combination with oral/topical antibiotic as antibiotics alone can only take care of opportunistic pathogens but do not have the ability to restore the vaginal microflora.

Although the study addresses the usefulness of the probiotic in management of BV, but certain limitations cannot be ruled out. The major limitations of this study was that it was not recorded whether subjects enrolled had recurrent BV with or without mixed infections and thereby the author did not take

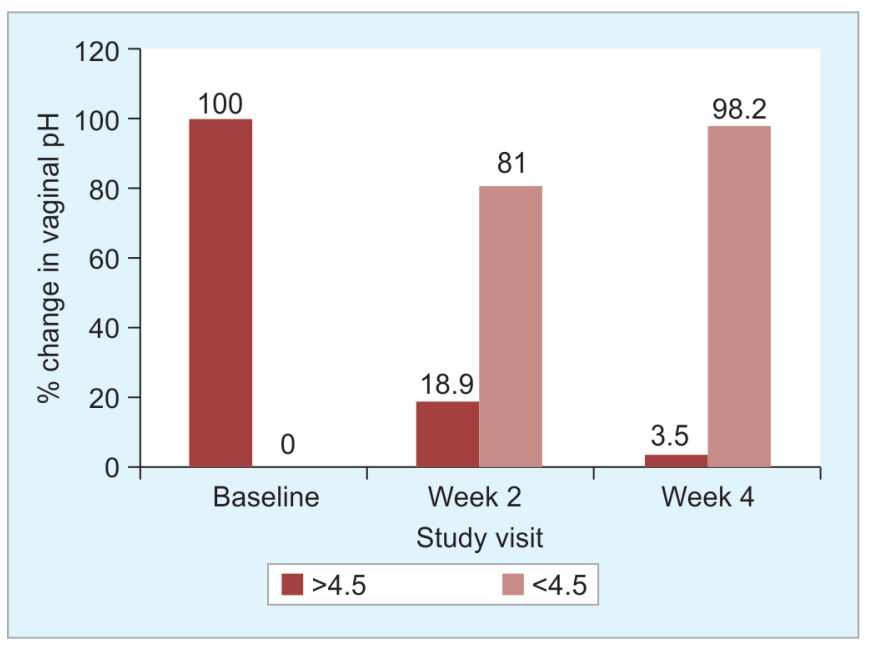

Fig. 3: Effect of probiotic on vaginal $\mathrm{pH}$

into consideration whether concomitant topical/oral antibiotics were used concomitantly.

\section{Conclusion}

The probiotic supplement with vaginal-specific lactobacilli strain has shown improvement in symptoms associated with BV and also decreases the chances of recurrence by restoring the microflora of the vaginal epithelium. Thus, either alone or in combination with antibiotics, vaginal-specific probiotics can be a preferred choice for correcting vaginal dysbiosis and its associated conditions.

\section{Clinical Significance}

Lactobacilli have been found in very low numbers in women suffering from BV. After supplementing probiotic, mere fall in $\mathrm{pH}<$ 4.5 indicates probable colonization of the vagina with the specific strain of lactobacilli has helped in production of lactic acid and restoration of the vaginal microflora.

\section{Manufacturer Name}

The probiotic supplement used in this study consisted of four strains of lactobacilli (L. crispatus and L. jensenii, L. iners, and L. gasseri) was manufactured by Mascot Health Series Pvt. Ltd., Plot No. 79, 80, Sec-6A, IIE, Sidcul, Haridwar-249403.

\section{ACKNOWLedgments}

The authors would like to express their thanks to Dr Uma Rani (MBBS, DGO), Dr Bharati Kalra (MD, Gynec), Dr Pritam Singh (Associate Professor, Department of Obstetrics and Gynecology), Dr Pragna Panchal (MS, Obs and Gynec), Dr V Padmaja (MD, Gynec), Dr Nirmala Devi (MBBS, DGO), Dr Uma Patil (MBBS, DGO), Dr Akshatha (MBBS, DGO), Dr Udayan Kundu (MBBS, DGO), Dr Dilip Modi (MD Gynec), Dr SD Sumer (Jr. Specialist, Obs and Gynec), Dr K Aruna Kumari (MD, Obs and Gynec), Dr RK Gupta (Medical Officer), Dr Minakshi Dubey (Medical Officer), Dr Priti Srivastava (Medical Examiner), and Dr Reena Kadia (MBBS, DGO). The authors are also thankful to Ms Kanchan Choudhary for helping to inscribe the manuscript and in performing the statistical analysis.

\section{References}

1. Vulvovaginal infections; viewed and dated on Feb 21, 2019. https:// www.cedars-sinai.edu/Patients/Health-Conditions/VulvovaginalInfections.aspx. 
2. Amit Singh, Vaibhav Kanti, Seema Dayal, et al. Prevalence and risk factors of bacterial vaginosis among women of reproductive age attending rural tertiary care institute of western Uttar Pradesh. J Evolution Med Dent Sci 2016;5(43):2695-2701. DOI: 10.14260/ jemds/2016/630.

3. Bacteria vaginosis (CDC, centers for disease control and prevention); viewed and dated on Feb 21, 2019. https://www.cdc.gov/std/tg2015/ bv.htm.

4. Wilson J. Managing recurrent bacterial vaginosis. Sex Transm Infect 2004;80(1):8-11. DOI: 10.1136/sti.2002.002733.

5. McClelland RS, Richardson BA, Hassan WM, et al. A prospective study of vaginal bacterial flora and other risk factors for vulvovaginal candidiasis. J Infect Dis 2009;199(12):1883-1890. DOI: 10.1086/599213.

6. Marschalek J, Farr A, Marie-Louise M, et al. Influence of orally administered probiotic lactobacillus strains on vaginal microbiota in women with breast cancer during chemotherapy: a randomized placebo-controlled double-blinded pilot study. Breast Care (Basel) 2017;12(5):335-339.

7. Reid G, Bruce AW. Urogenital infections in women: can probiotics help? Postgrad Med J 2003;79(934):428-432. DOI: 10.1136/pmj.79.934.428.
8. Akgül T, Karakan T. The role of probiotics in women with recurrent urinary tract infections. Turk J Urol 2018;44(5):377-383. DOI: 10.5152/ tud.2018.48742.

9. Redondo-Lopez V, Meriwether C, Schmitt C, et al. Vulvovaginal candidiasis complicating recurrent bacterial vaginosis. Sex Transm Dis 1990;17(1):51-53. DOI: 10.1097/00007435-19900100000011.

10. Swaminathan KR, Devi M, Gerald S, et al. Prevalence of vulvovaginal candidiasis in the women of the reproductive age, in rural India. Int J Clin Obstet Gynae 2017;1(2):37-39.

11. Gupta V, Nag D, Garg P. Recurrent urinary tract infections in women: how promising is the use of Probiotics? Indian J Med Microbiol 2017;35(3):347-354. DOI: 10.4103/ijmm.IJMM_16_292.

12. Astarte (HSO Health Care GmbH) Viewed and dated on Feb 21, 2019; http://www.astarte-probiotics.com/studies.

13. Kaufmann U, Domig KJ, Lippitsch $\mathrm{Cl}$, et al. Ability of an orally administered lactobacilli preparation to improve the quality of the neovaginal microflora in male to female transsexual women. Eur J Obstet Gynecol Reprod Biol 2014;172:102-105. DOI: 10.1016/ j.ejogrb.2013.10.019. 